\title{
Corrigendum: Data Citation in Neuroimaging: Proposed Best Practices for Data Identification and Attribution
}

\author{
Leah B. Honor ${ }^{1}$, Christian Haselgrove ${ }^{2,3}$, Jean A. Frazier ${ }^{2,3}$ and David N. Kennedy ${ }^{2,3 *}$ \\ ${ }^{1}$ Lamar Soutter Library, University of Massachusetts Medical School, Worcester, MA, USA, ${ }^{2}$ Eunice Kennedy Shriver Center, \\ University of Massachusetts Medical School, Worcester, MA, USA, ${ }^{3}$ Child and Adolescent NeuroDevelopment Initiative, \\ Department of Psychiatry, University of Massachusetts Medical School, Worcester, MA, USA
}

Keywords: data citation, data attribution, credit, data repository, data sharing

\section{A corrigendum on}

\section{OPEN ACCESS}

Edited by:

Richard A. Baldock,

MRC Human Genetics Unit, UK

Reviewed by:

Robert C. Cannon,

Textensor Limited, UK

*Correspondence:

David N. Kennedy

david.kennedy@umassmed.edu

Received: 13 September 2016

Accepted: 21 September 2016

Published: 05 October 2016

Citation:

Honor LB, Haselgrove C, Frazier JA and Kennedy DN (2016)

Corrigendum: Data Citation in

Neuroimaging: Proposed Best

Practices for Data Identification and Attribution. Front. Neuroinform. 10:43. doi: 10.3389/fninf.2016.00043
Data Citation in Neuroimaging: Proposed Best Practices for Data Identification and Attribution

by Honor, L. B., Haselgrove, C., Frazier, J. A., and Kennedy, D. N. (2016). Front. Neuroinform. 10:34. doi: 10.3389/fninf.2016.00034

In our original article, we stated, “Annual DOI creation costs range from $\$ 500$ (for non-degree granting departments) to $\$ 25,000$ (for entire degree-granting institutions) per 1 million DOIs minted." This is incorrect. The University of California EZID service offers annual DOI creation at $\$ 835$ (for non-degree granting departments) to $\$ 2500$ (for entire degree-granting institutions) per 1 million DOIs minted ${ }^{1}$. The authors apologize for the mistake. This error does not change the conclusions of the article in any way.

\section{AUTHOR CONTRIBUTIONS}

All authors contributed to the design, writing, and approval of this manuscript, and are accountable for its content.

\section{FUNDING}

This work was supported by NIH grants R01 MH083320 (NIMH and NLM) and P41 EB019936 (NIBIB).

Conflict of Interest Statement: The authors declare that the research was conducted in the absence of any commercial or financial relationships that could be construed as a potential conflict of interest.

Copyright $\odot 2016$ Honor, Haselgrove, Frazier and Kennedy. This is an open-access article distributed under the terms of the Creative Commons Attribution License (CC BY). The use, distribution or reproduction in other forums is permitted, provided the original author(s) or licensor are credited and that the original publication in this journal is cited, in accordance with accepted academic practice. No use, distribution or reproduction is permitted which does not comply with these terms.

${ }^{1}$ http://ezid.cdlib.org/learn/ 